\title{
EXPERIENTIAL MARKETING DAN SWITCHING BARRIERS TERHADAP CUSTOMER RETENTION DAN LOYALITAS PELANGGAN
}

\author{
Putri Nurjanah \\ Putrinurjanah1008@gmail.com \\ Juanim \\ Universitas Pasundan \\ Jl. Tamansari No. 6-8, Bandung 40116
}

diterima: 20/12/2019; direvisi: 26/7/2020; disetujui: 27/8/2020

\begin{abstract}
Customer loyalty is the main aspect of the company that needs to be maintained through a good, consistent, and long-lasting strategy. This study aims to determine the influence of experiential marketing and switching barriers on customer retention and their impact on customer loyalty at the Supratman branch of Togamas bookstore, Bandung. The method used is descriptive and verification methods. Nonprobability sampling with incidental method was used with a sample size of 100 respondents. The data analysis method used is path analysis, multiple correlation, and the coefficient of determination. The results showed that experiential marketing, switching barriers, and customer retention at the Togamas bookstore were good, while customer loyalty was good enough. The direct effect of experiential marketing on customer loyalty is greater than the indirect effect through customer retention. The indirect effect of switching barriers on loyalty is greater than the direct effect.
\end{abstract}

Keywords: experiential marketing; switching barriers; customer retention; customer loyalty; path analysis

\begin{abstract}
Abstrak
Loyalitas pelanggan merupakan aspek utama perusahaan, perlu dipertahankan melalui strategi yang baik, konsisten, dan tahan lama. Penelitian ini bertujuan untuk mengetahui besarnya pengaruh experiential marketing dan switching barriers terhadap customer retention dan dampaknya terhadap loyalitas pelanggan toko buku Togamas cabang Supratman Bandung. Metode yang digunakan adalah metode deskriptif dan verifikatif. Nonprobability sampling dengan metode incidental digunakan dan jumlah sampel 100 responden. Metode analisis data yang digunakan adalah analisis jalur, korelasi berganda, dan koefisien determinasi. Hasil penelitian menunjukkan bahwa experiential marketing, switching barriers, dan customer retention di toko buku Togamas baik, sedangkan loyalitas pelanggan cukup baik. Pengaruh langsung experiential marketing terhadap loyalitas pelanggan lebih besar dibandingkan dengan pengaruh tidak langsung melalui customer retention. Pengaruh tidak langsung switching barriers terhadap loyalitas lebih besar dibandingkan dengan pengaruh secara langsung.
\end{abstract}

Kata Kunci: experiential marketing; switching barriers; customer retention; loyalitas pelanggan; analisis jalur 


\section{PENDAHULUAN}

Indonesia merupakan negara berkembang yang memiliki laju pertumbuhan penduduk terus meningkat setiap tahunnya. Dibandingkan dengan negara di Asia Tenggara lainnya, Indonesia memiliki jumlah penduduk yang paling banyak yang mempengaruhi status pendidikan. Berdasarkan studi yang dilakukan Central Connecticut State University pada tahun 2016 mengenai most literate nations in the world menyebutkan Indonesia menempati urutan ke-60 dari total 61 negara. Rendahnya minat baca di Indonesia, menurut Colin McElwee, co-founder worldreader, dipengaruhi oleh sulitnya akses terhadap buku.

Tantangan industri buku Indonesia dihadapkan pada upaya keras menanamkan minat membaca di kalangan generasi muda di tengah masyarakat yang kental berbudaya lisan. Budaya baca yang tidak kuat, penetrasi teknologi digital sudah mulai mengalihkan perhatian orang dari membaca buku menjadi membaca gadget. Pergeseran dari membaca buku secara fisik ke arah digital, menciptakan perubahan perilaku konsumen saat berbelanja dan lebih banyak memilih berbelanja secara online.

Perusahaan harus memiliki strategi pemasaran, yaitu serangkaian keputusan dan tindakan yang menghasilkan formulasi dan implementasi rencana yang dirancang untuk mencapai tujuan perusahaan (Pearce, John A.; Robinson, 2011). Pemasaran tidak hanya berarti menjual produk, namun juga untuk memenuhi kepuasaan pelanggan sehingga selalu ingat terhadap produk yang telah dibelinya. Hal ini dapat membantu perusahaan untuk mempertahankan konsumen yang ada. Memiliki konsumen untuk tetap bertahan dan memberikan dampak positif pada perusahaan.

Perkembangan teknologi dan informasi, serta perilaku serta kebutuhan konsumen yang beragam mendorong berkembangnya kehidupan modern. Hal ini menjadi peluang usaha yang baik bagi pengusaha ritel, salah satunya yaitu toko buku. Beberapa nama toko buku yang selalu diingat konsumen ketika mereka akan berbelanja buku maupun alat tulis diantaranya yaitu toko buku Gramedia, Togamas, Gunung Agung, Karisma, dan Palasari.

Berdasarkan survei yang dilakukan oleh Top Brand Indonesia yang melibatkan 12.500 responden tercatat hampir 500 kategori produk dan menghasilkan lebih dari 1.000 merek yang mendapat predikat TOP. Ritel jenis toko buku diketahui bahwa Gramedia telah memimpin pasar toko buku sejak dulu hingga saat ini, yang ke dua yaitu Gunung Agung dan ke tigaTogamas.

Berdasarkan hasil survey yang dilakukan oleh top brand, toko buku Togamas memperoleh persentase paling rendah dan memiliki market share jauh berbeda dengan Gramedia. Pada kondisi demikian, Togamas masih mampu bertahan di tengah persaingan toko buku yang semakin ketat setiap tahunnya. Hal ini membuktikan bahwa masih ada pelanggan yang bertahan untuk melakukan pembelian atau bahkan hanya berkunjung. Togamas harus mampu menciptakan strategi strategi pemasaran, baik berorientasi kepada pelanggan maupun pendapatan agar dapat meningkatkan pangsa pasar dan menarik pengunjung baru yang memiliki potensi dalam meningkatkan pendapatan.

Memiliki konsep diskon seumur hidup, menjadikan daya tarik tersendiri bagi konsumen. Togamas masih memiliki banyak pengunjung yang datang, untuk setiap harinya minimal 1.000 pengunjung dan pada hari libur dapat mencapai 1.800. Begitupula pada saat pergantian semester maka jumlah pengunjung dapat meningkat.

Pada hari biasa, jenis buku yang paling banyak dibeli yaitu novel dengan jumlah 10.000 terjual dalam 2 minggu dan pembelian untuk buku Agama Islam minimal 20 Al-Quraan terjual dalam 10 hari. Pengunjung merasa tertarik terhadap konsep yang diusung oleh toko buku Togamas, selain itu ada lagi konsep lainnya diantaranya garansi buku seumur hidup, diskon pada jam tertentu, dan sampul gratis apabila berbelanja buku di atas tiga puluh ribu.

Peneliti melakukan survei pendahuluan yang dilakukan kepada 30 responden berdasarkan pertanyaan mengenai pemilihan toko buku offline yang dikunjungi. Hasilnya menunjukkan bahwa $33 \%$ responden memilih berbelanja buku dan alat tulis di toko buku Togamas, namun $67 \%$ pengunjung lebih memilih berbelanja di toko buku lainnya.

Berdasarkan top brand indeks, Togamas bukan yang pertama dalam memimpin pasar buku, rata-rata kunjungan Togamas tidak stabil. Pengunjung paling banyak memiliki frekuensi kunjungan 53\% tidak lebih dari satu kali dalam sebulan dan bahkan 50\% dari pengunjung membeli buku kisaran satu sampai dua buku saja, dapat dikatakan bahwa loyalitas konsumen pada toko buku Togamas masih rendah.

Tingkat loyalitas masih lemah yaitu pengunjung membeli karena adanya kemudahan faktor situasi. Rendahnya loyalitas pelanggan dapat mempengaruhi keberlangsungan usaha Togamas. Togamas sebaiknya menjaga loyalitas pelanggan yang masih ada dengan strategi menarik pelanggan bahkan pelanggan baru yang dianggap potensial. Seseorang dikatakan loyal kepada perusahaan apabila pelanggan tersebut menunjukkan perilaku pembelian tertentu yang ditandai oleh selang waktu berdasarkan pada serangkaian keputusan.

Menjaga loyalitas pelanggan adalah hal penting yang harus diperhatikan agar pelanggan tetap setia dalam menggunakan produk baik barang atau jasa dari perusahaan tersebut. Menjaga pelanggan tetap loyal secara ekonomi memiliki manfaat yang baik yaitu pelanggan yang loyal menggunakan produk perusahaan lebih banyak dan dalam waktu yang lebih lama (Kotler, Philip \& Amstrong, 2016)

Loyalitas sangat penting tetapi sangat sulit untuk mengukur dan memonitornya. Pengukuran mengukur 
loyalitas dapat dilakukan dari segi behavioral yaitu customer retention atau perilaku pembelian consume. Loyalitas dapat pula diukur dengan komponen sikap, keyakinan, perasaan. dan kehendak untuk melakukan pembelian. Retensi konsumen atau customer retention merupakan sebuah usaha yang dilakukan oleh perusahaan untuk memikat konsumen agar melakukan pembelian dalam jangka panjang di masa depan. Customer retention merupakan suatu bentuk loyalitas pelanggan dengan diwujudkan adanya perilaku pembelian terus menerus oleh konsumen dan dalam jangka panjang.

Togamas merupakan usaha ritel yang harus memperhatikan kebutuhan konsumen baik dari barang maupun pelayanan jasa, sehingga harus mampu memenuhi ekspektasi yang diinginkan pelanggan. Pengalaman fisik saja tidak memadai, harus dilengkapi dengan adanya pengalaman emosional. Experiential marketing adalah suatu usaha yang digunakan oleh perusahaan atau pemasar untuk mengemas produk sehingga mampu menawarkan pengalaman emosi hingga menyentuh hati dan perasaan konsumen. Experiential marketing dapat didefinisikan sebagai memori atau ingatan, juga pengalaman yang tertanam dalam pikiran juga perasaan seseorang. Experiential marketing membantu Togamas menciptakan diferensiasi dari toko buku lainnya, karena tidak sebagai pemimpin pasar.

Berdasarkan data yang diperoleh saat ini sangatlah banyak toko buku terutama di daerah Jawa Barat, sehingga konsumen dengan mudah berbelanja buku maupun peralatan tulis. Hal ini menjadi ancaman bagi Togamas karena semakin banyaknya pesaing dan kecilnya peluang konsumen untuk tetap berbelanja di Togamas.

Perusahaan harus menciptakan hambatan agar konsumen tidak pindah belanja ke tempat lainnya. Hambatan berpindah atau switching barriers, biasanya meliputi hambatan biaya (switching cost), hal yang menarik dari berbagai alternatif (attractiveness of alternatives), dan hubungan antar perorangan (interpersonal relationship). Upaya mempertahankan konsumen akan menekan biaya promosi di masa datang dibandingkan dengan harus menarik konsumen baru yang biayanya lebih mahal.

Experiential marketing atau sering disebut dengan pengalaman pelanggan adalah konsep yang mengintegrasikan unsur-unsur emosi, logika, dan proses pemikiran umum untuk menghubungkan dengan konsumen. Experiential marketing sangat berguna bagi perusahaan yang ingin meningkatkan merek yang berada pada tahap penurunan maupun untuk memperluas merek agar diketahui konsumen, membedakan produk mereka dari produk pesaing, menciptakan citra dan identitas perusahaan, meningkatkan inovasi, serta membujuk pelanggan untuk mencoba dan membeli produk.

Perkembangan teknologi informasi mempengaruhi perilaku setiap orang, sehingga perusahaan perlu lebih selaras dengan pelanggan seperti memberikan pengalaman yang menyentuh ketika melakukan pembelian produk maupun penggunaan jasa. Customer retention atau retensi pelanggan merupakan wujud ketertarikan batin pelanggan dan produsen yang ditandai dengan pembelian berulang dan memiliki sifat jangka panjang. Sehingga pelanggan akan tetap melakukan pembelian berjangka setiap mereka membutuhkannya. Penelitian (Budovich, 2019) menyatakan bahwa experiential marketing memiliki pengaruh terhadap meningkatnya retensi pelanggan, terutama pada perasaan yang positif.

Switching barriers atau disebut dengan hambatan berpindah merupakan suatu hambatan yang dirasakan oleh konsumen apabila mereka akan berpindah tempat berbelanja ke tempat lainnya. Hal ini akan menjadikan konsumen bertahan untuk tetap berbelanja di tempat mereka biasa berbelanja. Customer retention (retensi pelanggan) mengacu pada kemampuan suatu bisnis atau produk untuk mempertahankan pelanggannya selama beberapa periode tertentu. Customer retention yang tinggi berarti pelanggan dari produk atau bisnis cenderung untuk kembali atau melakukan pembelian berulang, terus membeli atau tidak berpaling ke produk atau bisnis lain, atau untuk non penggunaan seluruhnya.

Penciptaan hambatan ketika akan beralih ke perusahaan lainnya dapat dilakukan dengan membuat program yang menarik minat pelanggan, memberikan harga yang lebih murah di mata pelanggan maka akan mempertahankan pelanggan dalam jangka waktu tertentu, dan memberikan efek positif bagi perusahaan.

Penelitian (Liu et al., 2011) menunjukkan adanya hubungan switching barriers dengan customer retention. Hasil ini juga sesuai dengan peneltian yang dilakukan (Qonitat, 2018) bahwa secara simultan dan parsial kepuasan pelanggan, switching barriers, dan kepercayaan merek mempunyai pengaruh signifikan terhadap customer retention. Hasil penelitian (Nasrin Danesh et al., 2012) menunjukkan bahwa kepuasan pelanggan, kepercayaan dan switching barriers secara simultan dan parsial berpengaruh terhadap customer retention.

Setiap pelaku bisnis atau pemasar memiliki orientasi atau pandangan ke depan guna menjaga kestabilan kegiatan bisnis yang dijalani agar dapat bertahan di tengah persaingan pasar yang sangat ketat, baik itu berorientasi pada laba perusahaan maupun pada konsumen. Perusahaan harus mampu untuk mempertahankan pelanggan yang ada agar dapat melakukan pembelian secara berulang dan menjadi pelanggan yang loyal.

Upaya menciptakan pelanggan yang loyal harus dilakukan dengan menawarkan produk yang lebih unggul dibandingkan dengan pesaing. Tujuannya adalah agar pelanggan bersedia melakukan pembelian kembali sesuai dengan kebutuhan secara berkala. Hal 
inipun dibuktikan dengan penelitian yang dilakukan oleh (Martey, 2014) diperoleh hasil yang positif dan signifikan dengan empat variabel yaitu harga, kualitas pelayanan, kepuasaan pelanggan, citra merek dan variabel dependen loyalitas.

Pemasar dalam menjalankan bisnisnya membutuhkan startegi yang bersifat menghibur dan aktif, oleh sebab itu dibutuhkannya experiential marketing. Experience yang baik pada setiap pengunjung suatu perusahaan akan memiliki ikatan ketertarikan dan dapat membedakan kelebihan antara produk yang dimiliki dibandingkan dengan pesaing lainnya dan akan teringat di benak mereka. Konsumen yang sudah tertarik dengan perusahaan, maka selanjutnya tugas pemasar yaitu menciptakan loyalitas pelanggan, sehingga akan memiliki pengunjung tetap yang akan memberi pemasukan yang tetap juga pada perusahaan. Hal ini dibuktikan dengan penelitian (Chasanah et al., 2018) menunjukkan hasil yaitu semua dimensi sense, feel, think, act berpengaruh signifikan terhadap loyalitas pelanggan. Demikian pula penelitian yang dilakukan oleh (Sari, 2012), (Öztürk, 2015), (Setiawan, Susanto, 2018), serta (Manengkey, et al., 2019).

Menciptakan hambatan yang dirasakan konsumen apabila berpindah tempat berbelanja, seperti konsumen yang menilai bahwa harga yang ditawarkan oleh toko lebih murah dibanding pesaing dan apabila mereka berpindah belanja ke toko lain akan merasa rugi dengan biaya baik uang maupun waktu yang dikeluarkan lebih mahal dan membutuhkan banyak pengorbanan. Adanya hambatan ini akan menciptakan konsumen yang setia hanya dengan satu merek saja, dan akan melakukan pembelian berulang sesuai produk yang dibutuhkan bahkan produk lain yang diinginkan hal ini disebut juga dengan loyalitas.

Hal inipun sejalan dengan hasil penelitian (Howshigan \& Ragel, 2018) menunjukkan bahwa hambatan beralih berpengaruh positif dan signifikan terhadap retensi pelanggan. Selain itu penelitian (Maghfiroh, 2016), (Risdianto, G.E \& Japarianto, 2014), (Stan et al., 2013), dan (Juliani, 2015) menunjukkan adanya pengaruh positif dan signifikan switching barriers terhadap loyalitas.

Experiential marketing merupakan salah satu strategi pemasaran dalam memberikan pengalaman berbelanja yang menyenangkan dan menyentuh hati setiap perasaan konsumen, begitu juga dengan switching barriers adalah salah satu strategi agar konsumen tidak berpindah tempat berbelanja dan tetap melakukan pembelian kepada satu perusahaan saja. Melaksanakan dan mengembangkan strategi yang telah dimiliki dan menjalankan dengan baik serta tepat sasaran maka akan berpengaruh terhadap loyalitas pelanggan. Oleh karena itu suatu perusahaan harus memiliki strategi pemasaran yang dijadikan acuan dalam menjalankan promosi, merawat konsumen, dan mempertahankan keberlangsungan perusahaan.
Berdasarkan teori dan penelitian terdahulu, dapat dikemukakan hipotesis penelitian: (1) Terdapat pengaruh experiential marketing dan switching barriers terhadap customer retention retention, (2) Terdapat pengaruh customer retention terhadap loyalitas pelanggan, (3) Terdapat pengaruh experiential marketing dan switching barriers terhadap loyalitas pelanggan melalui customer retention.

\section{METODE}

Metode yang digunakan dalam penelitian ini adalah metode kuantitatif dengan pendekatan deskriptif dan verifikatif, dengan analisis jalur. Populasi pada penelitian ini adalah pengunjung Togamas Cabang Supratman Bandung, dengan sampel yang diperoleh berjumlah 100 responden. Teknik sampling yang digunakan adalah nonprobability sampling dengan menggunakan accidental sampling. Teknik pengumpulan data dengan menyebarkan kuesioner kepada pengunjung dengan skala interval. Metode korelasi pearson product moment digunakan untuk menguji validitas instrumen dan uji reliabilitas menggunakan metode Cronbach's alpha. Operasionalisasi variabel ditunjukkan pada Tabel 1.

\section{HASIL}

Uji validitas yang dilakukan pada experiential marketing, switching barriers, customer retention, dan loyalitas pelanggan dengan menggunakan 36 item pertanyaan semua dinyataka valid karena r-hitung yang diperoleh lebih besar dari r-tabel sebesar 0,300 . Uji reliabilitas yang dilakukan memiliki nilai Cronbach's alpha lebih besar dari nilai r-tabel sebesar 0,70, berarti keseluruhan dinyatakan reliabel. Berdasarkan hasil analisis deskriptif pada experiential marketing, switching barriers, customer retention berada pada kategori baik, sedangkan loyalitas pelanggan berada pada kategori cukup baik.

Analisis korelasi yang dilakukan pada substruktur I diperoleh nilai $\mathrm{R}$ sebesar 0,521 yang berarti experiential marketing dan switching barriers memiliki hubungan yang sedang terhadap customer retention. Nilai koefisien determinasi sebesar $27,1 \%$, dengan pengaruh positif dan signifikan. Secara parsial experiential marketing berpengaruh terhadap customer retention sebesar $9,30 \%$ dan switching barriers berpengaruh sebesar 17,70\%. Koefisien korelasi experiential marketing dengan switching barriers sebesar 0,598.

Analisis korelasi yang dilakukan pada substruktur II diperoleh hasil yaitu $\mathrm{R}$ sebesar 0,601 yang berarti experiential marketing, switching barriers, dan customer retention memiliki hubungan yang kuat terhadap loyalitas pelanggan. Nilai koefisien determinasi sebesar $36,1 \%$. Hasil uji simultan diperoleh pengaruh positif dan signifikan. Hasil uji parsial diperoleh experiential marketing berpengaruh terhadap loyalitas pelanggan 
sebesar 14,5\%, switching barriers berpengaruh sebesar $10,7 \%$, dan customer retention berpengaruh sebesar 10,9\%. Korelasi experiential marketing dengan switching barriers sedang yaitu 0,598 , korelasi experiential marketing dengan customer retention sedang yaitu 0,432, dan korelasi switching barriers dengan customer retention sedang yaitu 0,491 (Gambar 1 ).

Penggunaan analisis jalur dalam penelitian memperhitungkan adanya pengaruh langsung dan tidak langsung dan pengaruh total antar variabel penelitian. Pengaruh langsung experiential marketing terhadap retensi pelanggan adalah sebesar 7,9\%. Kemudian pengaruh experiential marketing terhadap loyalitas pelanggan melalui switching barriers sebesr 3,62\%. Sedangkan pengaruh experiential marketing terhadap loyalitas pelanggan melalui customer retention sebesar 2,87\%.

Pengaruh langsung switching barriers terhadap loyalitas pelanggan sebesar $4,6 \%$. Kemudian pengaruh switching barriers terhadap loyalitas pelanggan melalui experiential marketing sebesar $2,87 \%$. Sedangkan pengaruh switching barriers terhadap loyalitas pelanggan melalui customer retention sebesar 2,50\%.

Pengaruh paling besar terhadap loyalitas pelanggan secara langsung yaitu experiential marketing kemudian diikuti oleh customer retention, dan switching barriers. Pengaruh tidak langsung antara experiential marketing terhadap loyalitas pelanggan melalui customer retention lebih besar dibandingkan dengan pengaruh tidak langsung antara switching barriers terhadap loyalitas melalui customer retention (Gambar 2).

\section{PEMBAHASAN}

Customer retention atau retensi pelanggan merupakan bentuk pemeliharaan hubungan bisnis yang berkelanjutan dengan pelanggan dalam jangka waktu panjang. Menjaga retensi pelanggan merupakan hal penting yang harus diperhatikan oleh perusahaan, manajemen pelanggan adalah salah satu kunci untuk menjaga retensi pelanggan. Setiap pelanggan mempunyai harapan terhadap pelayanan dari perusahaan yang berkaitan contohnya layanan yang responsif, kualitas produk yang baik. Menjaga retensi pelanggan bisa saja dilakukan dengan selalu menjalin kerjasama yang baik.

Pengaruh experiential marketing terhadap customer retention yaitu sebesar $4,6 \%$. Hal ini menunjukkan bahwa experiential marketing yang terjadi di Togamas memiliki pengaruh yang positif dan signifikan, namun hanya memberikan pengaruh yang rendah terhadap customer retention. Dengan kata lain pengalaman berbelanja yang dirasakan oleh pelanggan belum menyentuh hati dan perasaan konsumen, semakin tinggi experiential marketing maka semakin tinggi juga customer retention. Menurut Khusnul Khotimah menyatakan bahwa experiential marketing merupakan metode yang utama dalam membangun komunikasi pemasaran.
Penelitian yang dilakukan oleh (Budovich, 2019) menyatakan bahwa mengiklankan emosional dapat mempengaruh peniaian konsumen ketika melakukan pembelian. Produk dan jasa yang berkualitas, inovatif, serta memberikan kenyamanan dan kepuasan yang baik pada pengunjung dapat memberikan pengaruh yang positif terhadap retensi pelanggan.

Customer retention merupakan suatu tindakan atau kegiatan perusahaan dalam mengurangi jumlah penurunan pelanggan, sehingga setiap pelanggan harus memiliki startegi dalam menarik dan mempertahankan pelaggan dengan meningkatkan produktivitas atau mutu baik produk maupun pelayanan dan diharapkan mampu menciptakan nilai pelanggan dan mengantisipasi agar pelanggan tidak berpindah ke toko buku lainnya. Salah satu upaya yang dilakukan adalah dengan membangun hambatan-hambatan yang mengikat pelanggan agar pelanggan tetap menggunakan produk dan jasa perusahaan terkait.

Pengaruh switching barriers terhadap customer retention sebesar 13,10\%. Hal ini menujukkan kekuatan hubungan yang rendah, namun tetap memiliki pengaruh yang positif dan signifikan. Berarti hambatan yang diciptakan Togamas masih sangat rendah dirasakan untuk mempengaruhi retensi pelanggan. Perusahaan yang memiliki switching barriers dapat menghambat pelanggan untuk beralih ke produk pesaing maupun pengguna jasa lainnya hal ini sesuai dengan apa yang disampaikan oleh (Qonitat, 2018) menyatakan semakin banyak hambatan terhadap produk maka semakin kecil pelanggan beralih produk lain. Penelitian yang dilakukan oleh (Ranaweera \& Prabhu, 2003), (Nasrin Danesh et al., 2012) diperoleh hasil yang positif dan signifikan antara switching barriers terhadap customer retention. Persamaan jalur substruktur I untuk mengetahui pengaruh experiential marketing $\left(\mathrm{X}_{1}\right)$ dan switching barriers $\left(\mathrm{X}_{2}\right)$ terhadap customer retention $(\mathrm{Y})$ adalah:

$$
\mathrm{Y}=0,216 \mathrm{X}_{1}+0,362 \mathrm{X}_{2}+0,729 \mathrm{e}_{1}
$$

Pelanggan loyal merupakan salah satu aspek utama yang harus dimiliki perusahaan. Pelanggan loyal perlu dipertahankan melalui strategi yang baik, konsisten, dan tahan lama. Harus mampu memikat hati dan perasaan konsumen menjadi lebih baik, riang, dan senang ketika berada di perusahaan pada saat melakukan pembelian. Konsumen akan selalu teringat bahwa berbelanja di perusahaan tersebut memberikan kesan tersendiri, menarik untuk selalu melakukan pembelian ulang, bahkan melakukan promosi dengan cara mengajak orang terdekat.

Berdasarkan hasil analisis diperoleh pengaruh positif dan signifikan experiential marketing terhadap loyalitas pelanggan sebesar 7,9\%, termasuk kategori rendah. Berarti pengalaman berbelanja di Togamas di kurang melekat dan menarik perhatian. (Sari, 
2012) menyatakan bahwa perusahaan perlu meninjau experiential marketing dengan meningkatkan perasaan dan pemikiran konsumen serta mepertimbangkan faktorfaktor lainnya yang berpengaruh terhadap loyalitas pelanggan, karena pengalaman pemasaran yang baik akan menciptakan dan mempertahankan pelanggan yang loyal (Manengkey et al., 2019). (Sari, 2012) menyatakan bahwa loyal atau tidaknya konsumen bukan dinilai dari sense marketing perusahaan, namun secara bersama-sama experiential marketing berpengaruh terhadap loyalitas pelanggan. Selanjutnya penelitian (Chasanah et al., 2018) dan (Manengkey et al., 2019) menyatakan bahwa experiential marketing berpengaruh positif terhadap loyalitas.

Pemasar pada umumnya menginginkan pelanggan yang datang dapat dipertahankan selamanya, terdapat beberapa faktor yang dapat mempertahankan pelanggan salah satunya yaitu switching barriers (hambatan berpindah). Dengan adanya hambatan untuk berpindah ke layanan lain membuat pelanggan menjadi loyal terhadap perusahaan kemudian melanjutkan hubungan pembelian dan akan melakukan pembelian ulang produk terhadap perusahaan dan enggan untuk berpindah ke layanan lainnya.

Switching barriers memiliki pengaruh positif dan signifikan terhadap loyalitas pelanggan sebesar 4,6\% dengan kategori rendah. Semakin tinggi switching barriers pada suatu perusahaan maka akan semakin tinggi juga loyalitas pelanggannya (Juliani, 2015). Selanjutnya penelitian yang dilakukan oleh (Maghfiroh, 2016), (Howshigan \& Ragel, 2018) menyatakan bahwa terdapat pengaruh positif dan signifikan switching barriers terhadap loyalitas pelanggan.

Setiap perusahaan mengetahui bahwa pelanggan yang loyal memiliki dampak yang besar bagi pendapatan perusahaan, pendapatan suatu perusahaan tercipta karena adanya konsumen yang melakukan pembelian ulang produk atau penggunaan pelayanan jasa perusahaan tersebut dan adanya pelanggan yang berkunjung dengan jangka waktu yang panjang. Retensi pelanggan merupakan bentuk loyalitas yang berhubungan dengan perilaku setia yang diukur berdasarkan perilaku beli konsumen yang ditunjukkan dengan tingginya frekuensi konsumen membeli suatu produk.

Hasil penelitian menunjukan pengaruh customer retention terhadap loyalitas pelanggan yaitu sebesar $5,6 \%$ berada pada rentang kategori rendah. Pemahaman tentang perilaku dan menjalin hubungan baik dengan pelanggan, menyediakan layanan yang baik, akan menciptakan loyalitas pelanggan (Singh \& Khan, 2012). Penelitian (Zulkifli, 2012) menunjukkan customer retention berpengaruh positif dan signifikan terhadap loyalitas pelanggan, dan bertahannya pelanggan karena adanya kepercayaan terhadap perusahaan. Penelitian (Martey, 2014) menunjukkan hubungan antara customer retention dan loyalitas konsumen adalah positif dan signifikan.
Persamaan substruktur II untuk mengetahui pengaruh experiential marketing (X1), switching barriers (X2) dan customer retention (Y) terhadap loyalitas pelanggan $(\mathrm{Z})$ pada toko buku Togamas cabang Supratman, dapat dirumuskan sebagai berikut:

$$
Z=0,282 X_{1}+0,215 X_{2}+0,236 Y
$$

Experiential marketing berpengaruh secara tidak langsung terhadap loyalitas pelanggan sebesar 6,49\% sedangkan pengaruh langsung 7,9\%. Terlihat bahwa pengaruh secara langsung lebih besar dari pada pengaruh tidak langsung. Switching barriers berpengaruh tidak langsung terhadap loyalitas pelanggan sebesar $6,12 \%$ dan pengaruh langsung $4,6 \%$. Berarti pengaruh langsung lebih kecil daripada pengaruh tidak langsung.

Berdasarkan kedua persamaan yang telah diuraikan, dapat disimpulkan bahwa customer retention tidak mampu memperkuat hubungan antara experiential marketing terhadap loyalitas pelanggan, namun variabel customer retention mampu memperkuat hubungan antara variabel switching barriers terhadap loyalitas pelanggan.

\section{KESIMPULAN}

Tanggapan respoden terkait experiential marketing, swtching barriers, cutomer retention pada Toko Buku Togamas termasuk dalam kategori baik, sedangkan loyalitas pelanggan cukup baik. Experiential marketing dan switching barriers berpengaruh langsung terhadap customer retention dan loyalitas pelanggan. Customer retention berpengaruh terhadap loyalitas pelanggan. Pengaruh tidak langsung experiential marketing terhadap loyalitas pelanggan lebih kecil dibandingkan dengan pengaruh secara langsung dan pengaruh tidak langsung switching barriers terhadap loyalitas pelanggan lebih besar dibandingkan pengaruh secara langsung. Berarti customer retention tidak dapat memediasi experiential marketing tetapi memediasi switching barriers terhadap loyalitas pelanggan.

\section{DAFTAR PUSTAKA}

Budovich, L. S. 2019. Experiential marketing as a basis for modern communications with consumers. Espacios, 40(6), 79-85.

Chasanah, R. N., Muzammil, O. M., \& Rowena, J. 2018. Pengaruh Experiential Marketing Terhadap Keputusan Pembelian Konsumen Generasi Millenial Pada Platform E-Commerce. National Conference of Creative Industry, September, 5-6. https://doi. org/10.30813/ncci.v0i0.1276

Howshigan, S., \& Ragel, V. R. 2018. The Effectiveness of Switching Barrier on Customer Loyalty Mediated with Customer Satisfaction: Telecommunication Industry, Batticaloa. South Asian Journal of Social Studies and Economics, 2(2), 1-9. https://doi. 
org/10.9734/sajsse/2018/v2i225833

Juliani, F. A. 2015. Pengaruh Switching Barrier Terhadap Loyalitas Pelanggan. Ilmu Manajemen, 2(April), 131-134.

Kotler, Philip \& Amstrong, G. 2016. Principle of Marketing (16th Globa).

Liu, C. T., Guo, Y. M., \& Lee, C. H. 2011. The effects of relationship quality and switching barriers on customer loyalty. International Journal of Information Management, 31(1), 71-79. https:// doi.org/10.1016/j.ijinfomgt.2010.05.008

Maghfiroh, S. 2016. Pengaruh Kepuasan, Antusiasme, Dan Switching Barrier Terhadap Loyalitas Anggota Pada Koperasi Serba Usaha. Economic Education Analysis Journal, 5(1), 290-300.

Manengkey, V. M., Tumbel, T. M., \& Kalangi, J. A. F. 2019. Pengaruh Experiential marketing Terhadap Loyalitas Pelanggan Kebun Strawberry D'MOOAT. Jurnal Administrasi Bisnis, 9(1), 64. https://doi. org/10.35797/jab.9.1.2019.23558.64-71

Martey, E. M. 2014. The Relationship between Customer Retention and Customer Loyalty in the Restaurant Industry in Ghana.

Nasrin Danesh, S., Ahmadi Nasab, S., \& Choon Ling, K. 2012. The Study of Customer Satisfaction, Customer Trust and Switching Barriers on Customer Retention in Malaysia Hypermarkets. International Journal of Business and Management, 7(7), 141-150.

Öztürk, R. 2015. Exploring the Relationships between Experiential Marketing, Customer Satisfaction and Customer Loyalty: An Empirical Examination in Konya. International Journal of Social, Behavioral, Educational, Economic and Management Engineering, 9(8), 2485-2488. www.citeulike.org/ user/tilljwinkler/article/10083551.

Pearce, John A.; Robinson, R. B. 2011. Strategic
Management: Formulation, Implementation, and Control (11th ed.). McGraw-Hill.

Qonitat, N. N. 2018. Pengaruh Kepuasan Pelanggan, Switching Barrier dan Kepercayaan Merk Terhadap Customer Retention.

Ranaweera, C., \& Prabhu, J. 2003. The influence of satisfaction, trust and switching barriers on customer retention in a continuous purchasing setting. International Journal of Service Industry Management, 14(3-4), 374-395. https://doi. org/10.1108/09564230310489231

Risdianto, G.E \& Japarianto, E. 2014. Pengaruh Customer Satisfaction Dan Switching Barriers Terhadap Customer Loyalty Dengan Menggunakan Variabel Customer Trust Sebagai Variabel Moderating Pada Toko Buku Petra Togamas Surabaya. Jurnal Manajemen Pemasaran, 10.

Sari, M. K. 2012. Pengaruh Penerapan Experiential Marketing Terhadap Loyalitas Konsumen Kartu Pra Bayar Simpati Telkomsel. Economica, 1(1), 86-96. https://doi.org/10.22202/economica.2012.v1.i1.108

Setiawan, Susanto, dan N. 2018. The Effect Of Experiential Marketing On Visitor Satisfaction And Visitor Loyalty. 5, 14-22.

Singh, R., \& Khan, I. A. 2012. An Approach to Increase Customer Retention and Loyalty in B2C World. International Journal of Scientific and Research Publications, 2(6), 1-5. http://www.ijsrp.org/ research_paper_jun2012/ijsrp-June-2012-40.pdf

Stan, V., Caemmerer, B., \& Cattan-jallet, R. 2013. Customer Loyalty Development : The Journal of Applied Business Research, 29(5), 1541-1554.

Zulkifli. 2012. Relationship Marketing Terhadap Customer Retention dan Customer Loyalty pada Nasabah Bank Mega, Tbk. Malang. Jurnal Manajemen dan Akuntansi, 1(April), 1-12.

Tabel 1. Pengaruh Langsung dan Tidak Langsung Experiential Marketing, Switching Barriers dan Customer Retention Terhadap Loyalitas Pelanggan

\begin{tabular}{|c|c|c|c|c|c|c|}
\hline \multirow{2}{*}{ Variabel } & \multirow{2}{*}{$\begin{array}{l}\text { Pengaruh } \\
\text { Langsung }\end{array}$} & \multicolumn{3}{|c|}{$\begin{array}{l}\text { Pengaruh Tidak } \\
\text { Langsung Melalui }\end{array}$} & \multirow{2}{*}{$\begin{array}{l}\text { Total Pengaruh } \\
\text { tidak langsung }\end{array}$} & \multirow{2}{*}{$\begin{array}{c}\text { Total } \\
\text { Pengaruh }\end{array}$} \\
\hline & & $\mathrm{X}_{1}$ & $\mathrm{X}_{2}$ & Y & & \\
\hline Experiential Marketing & 7,9 & & 3,62 & 2,87 & 6,49 & 14,40 \\
\hline Switching Barriers & 4,6 & 3,62 & & 2,50 & 6,12 & 10,72 \\
\hline Customer Retention & 5,6 & 2,87 & 2,5 & & 5,37 & 10,97 \\
\hline Total & 18,1 & 6,49 & 6,12 & 5,37 & 17,98 & 36,07 \\
\hline
\end{tabular}

Sumber: Hasil Pengolahan Data 2020 


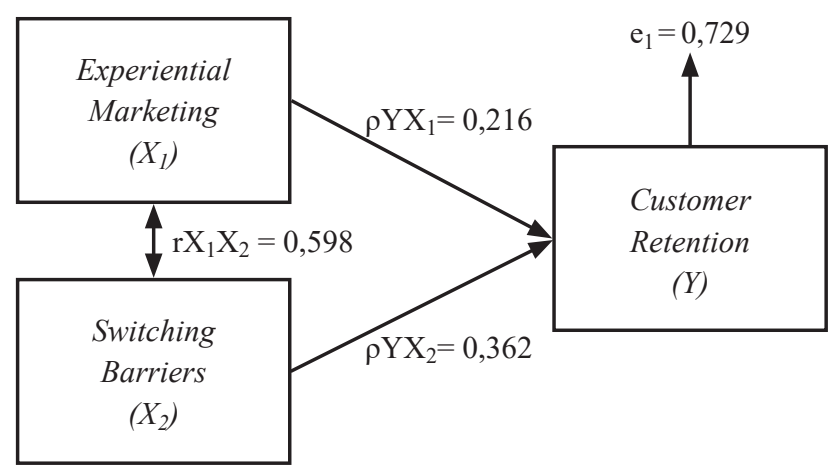

Gambar 1. Diagram Jalur Substruktur I

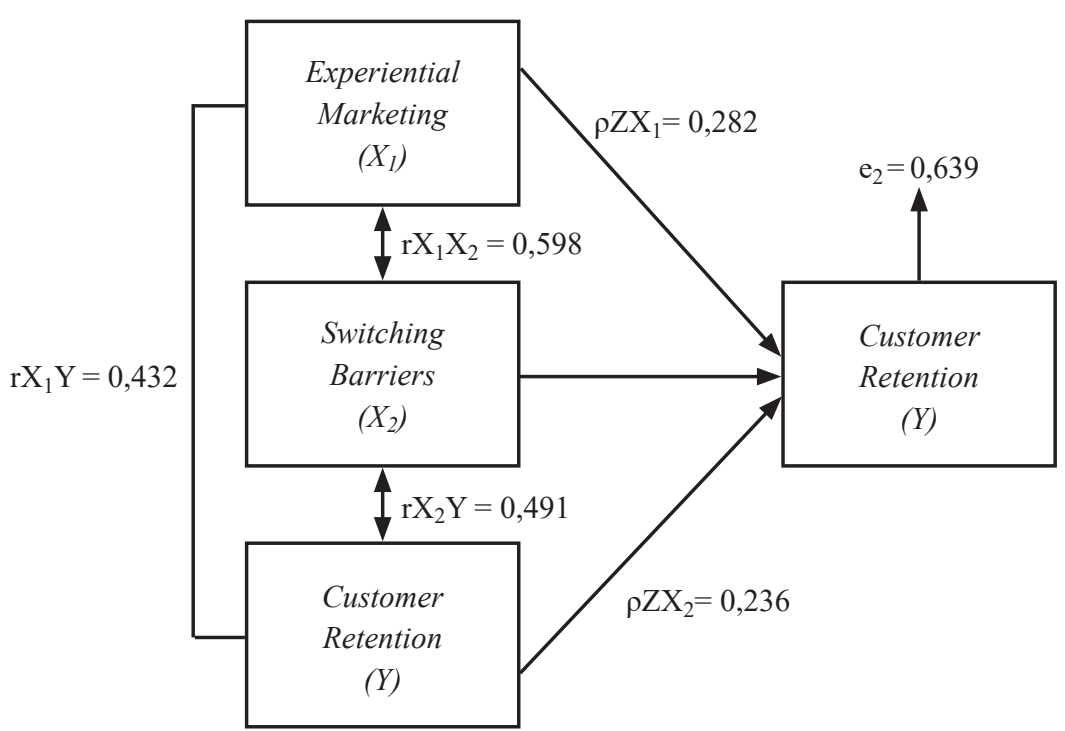

Gambar 2. Diagram Jalur Substruktur II 